\title{
Fifty years of research on the physiology and pharmacology of the autonomic nervous system
}

\author{
Derek Frewin $^{1}$
}

Received: 2 January 2021 / Accepted: 4 January 2021 / Published online: 22 January 2021

○) Springer-Verlag GmbH Germany, part of Springer Nature 2021

To commemorate the 30th anniversary of Clinical Autonomic Research a journal whose first editorial board I had the honor to be part of I relate some of my professional experiences in autonomic medicine, in particular in physiology and pharmacology.

My first serious interaction with the autonomic nervous system was in 1966 when I registered as a candidate for a Doctorate in Medicine (M.D.) degree, in the department of Human Physiology and Pharmacology at the University of Adelaide. Until then, my knowledge of the autonomic nervous system was restricted to what had been covered within my undergraduate medical program and particularly its relationship to the functioning of the cardiovascular system, the alimentary tract, and thermoregulation.

The supervisors for my Doctorate degree were Professor Robert (Bob) Whelan and Professor Ivan de la Lande. Whelan was the head of the department with de la Lande as his deputy. They both had a significant interest in the autonomic nervous system. Bob Whelan came from Queen's University in Belfast (Northern Ireland), where he was a member of a formidable team of cardiovascular physiologists (Roddie, Shepherd, and Whelan) who had published extensively on the control of the peripheral circulation in man. Much of their work involved forearm and hand plethysmography and the study of drugs and exercise on the human circulation. Thus, I was blooded into the art of plethysmography soon after I began my degree. Professor de la Lande, on the other hand, was a biological scientist with a Ph.D. from Melbourne University and his role was to teach me the use of the isolated, perfused central artery of the rabbit ear to study the effects of sympathetic innervation on vascular sensitivity to noradrenaline [1]. We developed a fluorescent histochemical technique to examine catecholamine

Derek Frewin

derek.frewin@bigpond.com

1 Department of Cardiology, Royal Adelaide Hospital, 1 Port Road, Adelaide, SA 5000, Australia fluorescence in a variety of human and primate blood vessels, and concluded that the sympathetic nerve endings in the blood vessels are located at the medio-adventitial junction $[5,8,11]$.

In addition, we conducted plethysmography studies on the human forearm and demonstrated that both tyramine and ephedrine were indirectly acting sympathomimetics, whose constrictor action on this vascular bed was very dependent on the presence of sympathetic nerves $[9,10]$. We further demonstrated the enhancement of the vasoconstrictor action of tyramine, methylamphetamine, and ephedrine by the monoamine oxidase inhibitor tranylcypromine [6]. This finding provided us with a platform to use monoamine oxidase inhibitors, fludrocortisone, and even cheese to increase blood pressure and improve orthostatic symptoms in patients with idiopathic orthostatic hypotension [7, 13].

Because of our interest in autonomic function testing, we received many requests from the Royal Adelaide Hospital, and also from specialists and general practitioners, to evaluate their patients. This led to some interesting reports, among them three cases of orthostatic hypotension with autonomic failure [4]. One of these was a 40-year-old woman with widespread autonomic nervous system degeneration associated with peripheral sensory and motor neuropathy and the Holmes-Adie syndrome. Her autopsy showed widespread amyloid deposition in the sympathetic ganglia, peripheral nerves, heart, and the gastrointestinal system, as the pathological basis for her clinical and physiological findings. We also studied patients with diabetic autonomic neuropathy [2].

I was able to transport my interest in the autonomic nervous system to the department of Rehabilitation Medicine at the College of Physicians and Surgeons of Columbia University in New York, where I was fortunate to work as a Fulbright Scholar in the 1970s. The head of the unit at Columbia (Dr. John Downey) and I had worked closely together in Adelaide and he kindly arranged for a complete set of autonomic testing equipment for me. Also, Dr. Downey's 
laboratory was very well set up for testing sweating responses. We studied these responses in normal, paraplegic, and anhidrotic subjects using the technique of resistance hygrometry [12], which added a quantitative assessment to the qualitative tests (starch-iodine and quinizarin) we had used previously.

Whilst in New York, I became very interested in examining the role of the enzyme dopamine $\beta$-hydroxylase $(D \beta H)$ as a marker of sympathetic nerve activity. We were able to collaborate with scientists at the New York State Psychiatric Institute in this respect and study the effect of heat, cold, and exercise on $\mathrm{D} \beta \mathrm{H}$ [3]. Upon returning to Adelaide, we conducted further studies on $\mathrm{D} \beta \mathrm{H}$ but found that the relationship between the levels of $\mathrm{D} \beta \mathrm{H}$ and the sympathetic nerve activity was not as tight as with plasma noradrenaline levels.

I maintained my interest in the autonomic nervous system thereafter. However in the mid-1970s became more and more involved with running the Hypertension Clinic at the Royal Adelaide Hospital. Whilst this role principally involved managing patients with primary and secondary hypertension, I continued to receive requests for autonomic testing and the treatment of patients with orthostatic hypotension. We developed an assay for plasma catecholamines which we used both in the diagnosis of pheochromocytoma and also in studies with many anesthetic agents. Perhaps the most clinically difficult situation I had to manage involved patients with significant orthostatic hypotension and severe supine hypertension, in which we tried empirically with pindolol, a $\beta$-adrenergic blocker with intrinsic sympathomimetic activity, and coenzyme Q10 with some benefit.

Prof. Christopher Mathias, the founding editor of Clinical Autonomic Research, and I had known each other for many years and we still keep in contact. I was delighted when he invited me to join the editorial board of Clinical Autonomic Research in 1990. It was the first journal ever to be devoted to the autonomic nervous system with an emphasis on clinical medicine. I am very pleased to see that it is now the benchmark journal for autonomic medicine, enjoying a considerable impact and reputation among the scientific community. I have greatly enjoyed my research in autonomic medicine over the last fifty years and, although retired from laboratory work, will continue to follow the development of the field with great interest.
Funding None.

\section{Compliance with ethical standards}

Conflicts of interest None.

\section{References}

1. De la Lande IS, Frewin D, Waterson JG (1967) The influence of sympathetic innervation on vascular sensitivity to noradrenaline. Br J Pharmacol Chemother 31:82-93

2. Frank HJ, Frewin DB, Robinson SM, Wise PH (1972) Cardiovascular responses in diabetic dysautonomia. Aust N Z J Med 2:1-7

3. Frewin DB, Downey JA, Levitt M (1973) The effect of heat, cold, and exercise on plasma dopamine-beta-hydroxylase activity in man. Can J Physiol Pharmacol 51:986-989

4. Frewin DB, Gilmore HR, Ho JQ, Scroop GC (1968) Clinical, physiological and pathological observations in a case of progressive autonomic nervous system degeneration associated with Holmes-Adie syndrome and peripheral neuropathy. Aust Ann Med 17:141-147

5. Frewin DB, Hume WR, Waterson JG, Whelan RF (1971) The histochemical localisation of sympathetic nerve endings in human gingival blood vessels. Aust J Exp Biol Med Sci 49:573-580

6. Frewin DB, Jellett LB, Whelan RF (1969) Modification of the vasoconstrictor action of sympathomimetic agents by bretylium tosylate and tranylcypromine in man. Br J Pharmacol 36:602-610

7. Frewin DB, Robinson SM, Willing RL (1973) The use of a new mode of therapy in the management of orthostatic hypotension. Aust N Z J Med 3:180-183

8. Frewin DB, Waterson JG, Whelan RF (1971) Catecholamine fluorescnece in primate digital arteries. Aust J Exp Biol Med Sci 49:421-424

9. Frewin DB, Whelan RF (1968) The action of ephedrine on forearm blood vessels in man. Aust J Exp Biol Med Sci 46:425-434

10. Frewin DB, Whelan RF (1968) The mechanism of action of tyramine on the blood vessels of the forearm in man. Br J Pharmacol Chemother 33:105-116

11. Gerke DC, Frewin DB, Soltys JS (1975) Adrenergic innervation of human mesenteric blood vessels. Aust J Exp Biol Med Sci $53: 241-243$

12. Huckaba CE, Frewin DB, Downey JA, Tam HS, Darling RC, Cheh HY (1976) Sweating responses of normal, paraplegic and anhidrotic subjects. Arch Phys Med Rehabil 57:268-274

13. Mahar LJ, Frewin DB, Dunn DE (1975) Idiopathic orthostatic hypotension controlled with a monoamine oxidase inhibitor and 9-alpha-fluorohydrocortisone. Med J Aust 2:940-943 